4. BYOD trend has force in Ukraine. Available at: http://www.pcweek.ua/themes/detail.php?ID=143082

5. BYOD - Research findings released. Available at: http://cxounplugged.com/2013/01/byod-policy/

6. BYOD Requires Mobile Device Management. Available at: http://www.informationweek.com/mobile/byodrequires-mobile-device-management/d/d-id/1097576?

7. Mobile device management (MDM). Available at: $\mathrm{http} / / /$ searchmobilecomputing.techtarget.com/definition/mobile -device-management

8. No BYOD Policy? Time to grasp the nettle. Available at: http://cxounplugged.com/2013/01/byod-policy/

9. Rafael Ballagas, Michael Rohs, Jennifer G. Sheridan, and Jan Borchers. BYOD: Bring Your Own Device. Available at: http://www.vs.inf.ethz.ch/publ/papers/rohs-byod-2004.pdf

Рекомендовано до публікаиії д-р фіз.-мат. наук Михайлюк В. О. Дата надходження рукопису 25.11.2014

Мартинюк Олександр Олександрович, Фізико-технічний інститут, Національний технічний університет України „Київський політехнічний інститут”, пр. Перемоги, 37, м. Київ, Україна, 03056

E-mail: oleksandr_lutsk@ukr.net

УДК 656.225:629.463

DOI: 10.15587/2313-8416.2014.31645

\title{
МОДЕЛИРОВАНИЕ ПРОЦЕССА ОБРАБОТКИ ГРУЗОВОГО ВАГОНОПОТОКА НА ПРИГРАНИЧНОЙ СТАНЦИИ В УСЛОВИЯХ ИЗМЕНЕНИЯ ШИРИНЫ КОЛЕИ
}

\author{
(С) Д. В. Ломотько, А. Л. Обухова
}

Предложен подход к оценке параметров вагонопотока на приграничных станичия с изменением ширинь коли. Моделирование технологии осуществлено с использованием теории систем массового обслуживания с учетом фактора сложности технологии обработки вагонопотока в подсистемах станции. Осуществлена оценка параметров системы и отдельных технологических линий, обеспе чивающих повыщение показателей результативности работы - пропускной и перерабатывающей способности

Ключевые слова: железная дорога, пограничная станция, технологический процесс, вагонопоток, изменение иирины колеи

An approach to the estimation of wagon cargo parameters at border stations with railway track gauge change is proposed. Technology simulation is carried out using the theory of queuing systems, taking into account the complexity factor of wagon cargo traffic processing in the station subsystems. It is made the estimation of system parameters and separate production lines that enhance the work efficiency indicators- traffic and handling capacity

Keywords: railway, border station, technological process, wagon cargo traffic, railway track gauge change

\section{1. Введение}

Приграничные станции являются важнейшими звеньями, от четкости работы которых зависит равномерность и ритмичность работы международных транспортных коридоров, сроки доставки грузов, степень использования технических средств транспорта.

В частности, наиболее сложными с технологической точки зрения являются приграничные станции с изменением ширины колеи. Структуру перерабатывающих возможностей перегрузочных комплексов, расположенных на территории Львовской железной дороги, приведено на рис. 1.

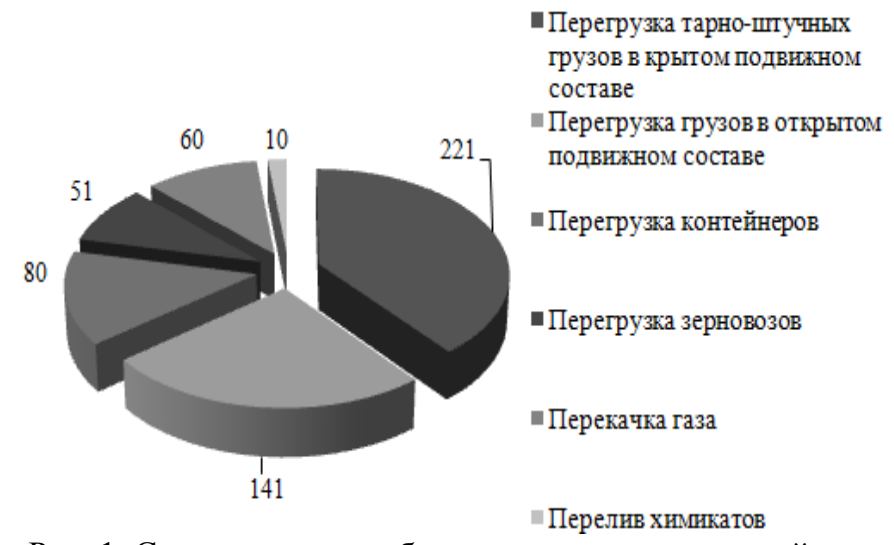

Рис. 1. Структура перерабатывающих возможностей перегрузочных комплексов, расположенных на территории Львовской железной дороги, ваг/сут 
В свою очередь, приграничные станции, являются сложными системами, состоящими из ряда подсистем с отдельными линиями общего процесса, обеспечивающих его результативную мощность пропускную и перерабатывающую способности. В технологическом процессе приграничной передаточной станции рассматриваются технологические линии обработки вагонопотоков и документов. Данные логистические потоки, - материальный и информационный, являются самостоятельными, однако взаимосвязанными и взаимозависимыми друг от друга.

\section{2. Постановка проблемы}

Технология работы этих линий базируется на установившихся режимах, позволяющих заранее определять общий ход процесса переработки экспортно-импортного вагонопотока. Прогнозирование поведения сложной системы, какой является пограничная станция, необходимо для правильного принятия управленческих решений на различных уровнях управления продвижением вагонопотоков.

Однако, принимая во внимание сложность системы в целом, необходимо учитывать, что указанные режимы не всегда являются постоянными и могут определяться только последовательным набором отдельных событий, характеристика которых проявляется только в ходе выполнения операций. Это зависит от продолжительности выполняемых операций, которые в свою очередь зависят от целого ряда объективных и субъективных факторов, а также имеет вероятностный характер. При этом размах изменения случайной величины ограничен допустимыми пределами, поскольку транспортный процесс не может быть чисто случайным. Установление этих границ возможно с помощью статистических исследований работы реальных приграничных станций и отдельных их звеньев.

\section{3. Литературный обзор}

Исследования, проведенные различными учеными, доказали, что значительная часть транспортных потоков удовлетворительно описывается законами распределения Пуассона, Эрланга, биноминальным и нормальным. Статистические исследования погранично-передаточных станций показали, что в настоящее время интервалы между поездами, поступающих на станцию и выходят из станции, а также распределение времени обслуживания заявок, поступающих на станцию, описываются законами Пуассона и Эрланга 2-го порядка. Вентцель Е. С. в монографии «Исследование операций» о потоке Пуассона говорит, что «... простейший поток - это «Наименее регулярный» из встречающихся на практике потоков» [1].

В [2] были рассмотрены варианты технических решений вопроса различной ширины колеи 1520/1435 мм. Применение прогрессивной технологии автоматизированных раздвижных колесных пар позволит добиться сокращения простоя вагонов на станции. Однако, как было отмечено, характер ограничения также носит процесс обработки документов работниками станции и органами государственного контроля.

В [3] приведена модель оптимизации расходов транспортно-логистической системы (ТЛС), в которую входят множество параметров, характеризующих материальные потоки и множество параметров, характеризующих информационные потоки в ТЛС. Суть данной модели возможно применить к технологии работы пограничной станции, особенно с учетом ее взаимосвязанной работы с пунктом где выполняется переход на другую ширину колеи.

Таким образом, модель оптимизации затрат подсистемы «приграничная станция - пункт перегрузки вагонов», которая учитывает связь информационного и материального потоков, в неявном виде имеет вид

$$
\begin{aligned}
& S=F\left\{f\left(M^{\Pi \Pi I}\left[I_{M}, X_{M}, Y_{M}\right]\right),\right. \\
& \left.f\left(I^{\Pi \Pi I}\left[I_{I}, X_{I}, Y_{I}\right]\right), S_{t}^{\Pi \Pi}\right\} \rightarrow \min ,
\end{aligned}
$$

при ограничениях

$$
\left\{\begin{array}{l}
I_{M} \leq I_{M}^{\max } \\
I_{I} \leq I_{I}^{\max } \\
\left|I_{t}-M_{t}\right| \leq \delta,
\end{array}\right.
$$

где $S$ - общие затраты в системе «пограничная станция - пункт перегрузки вагонов» (ПП); $M^{\text {ПП }}$ множество параметров, характеризующих материальные потоки в системе ПП; $I_{M}$ - интенсивность материального потока; $X_{M}-$ множество входных показателей системы ПП, характеризующие поток М; $Y_{M}$ - множество выходных показателей системы ПП, характеризующие поток М; $I^{\text {ПI }}$ - множество параметров, характеризующих информационные потоки в системе ПП; $I_{I}-$ интенсивность информационного потока; $X_{I}$ - множество входных показателей системы ПП, характеризующие поток I; $Y_{I}$ - множество выходных показателей системы ПП, характе-

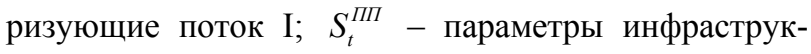
туры системы ПП, обеспечивает продвижение материальных и информационных потоков; $I_{M}^{\max }-$ максимальная интенсивность материального потока, переработку которого обеспечивает инфраструктура системы ПП; $I_{I}^{\max }$ - максимальная интенсивность информационного потока, обработку которого обеспечивает инфраструктура системы ПП; $I_{t}-$ продолжительность обработки информационного потока во времени в системе ПП; $M_{t}$ - продолжительность переработки материального потока во времени в системе ПП; $\delta$ - заранее заданная своевременность доставки груза.

Величина $S_{t}^{I I I}$ - параметр, относительно системы «приграничная станция - пункт перегрузки вагонов» включает как перерабатывающие способности подсистем станции, так и перера-батывающую 
способность пункта перехода вагонов согласно технологического решения, которое реализуется (перегрузка, изменение тележек).

\section{4. Исследование грузового вагонопотока на приграничной станции}

Известно, что функционирование любой станции можно интерпретировать с помощью сети систем массового обслуживания. Эта сеть состоит из нескольких последовательно и параллельно действующих систем обслуживания, в полной мере оказывающих взаимное влияние.

Получение достоверных результатов для планирования оперативной работы приграничных станций зависит от математической модели функционирования станций, которая принимается для расчетов. Выбор той или иной математической модели, или математического аппарата решения задачи в целом, зависит от анализа интервалов входных поездопотоков на станцию и потоков обслуживания в каждой подсистеме станции.

Для исследования структуры входного потока первичной статистикой является случайный интервал времени между двумя поездами, последовательно прибывающими на станцию. Случайный характер поступления приводит к тому, что в определенные моменты на входе в систему массового обслуживания образуется очередь, а в другие периоды времени часть каналов простаивают [4-6].

Для приведения выбранной системы массового обслуживания в соответствие с существующими размерами поездопотоков, а также учитывая, что динамику модели задают входные потоки и потоки обслуживания, был проведен анализ структуры и оценка параметров поездопотоков обслуживания. Для этих целей был собран статистический материал на некоторых пригранично-передаточных станциях Укрзалізниці.

Результаты обработки статистических данных входного потока приведены на рис. 2. Установлено, что распределение интервалов времени между грузовыми поездами, поступающих на приграничную станцию, вне зависимости от сезона подчинено экспоненциальному закону.

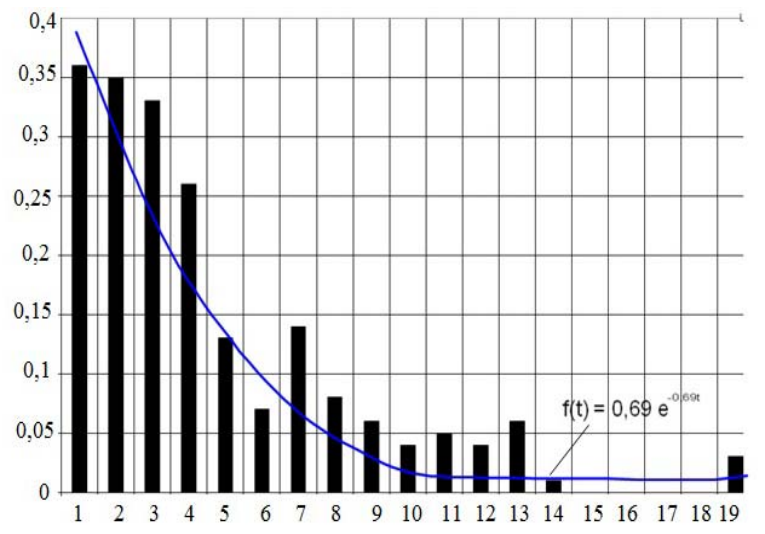

Рис. 2. Гистограмма распределения входного потока составов на станцию за июнь-август 2014

Распределение интервалов времени между отправляемыми грузовыми поездами - выходного потока составов с приграничной передаточной станции - также подчинено экспоненциальному закону (рис. 3).

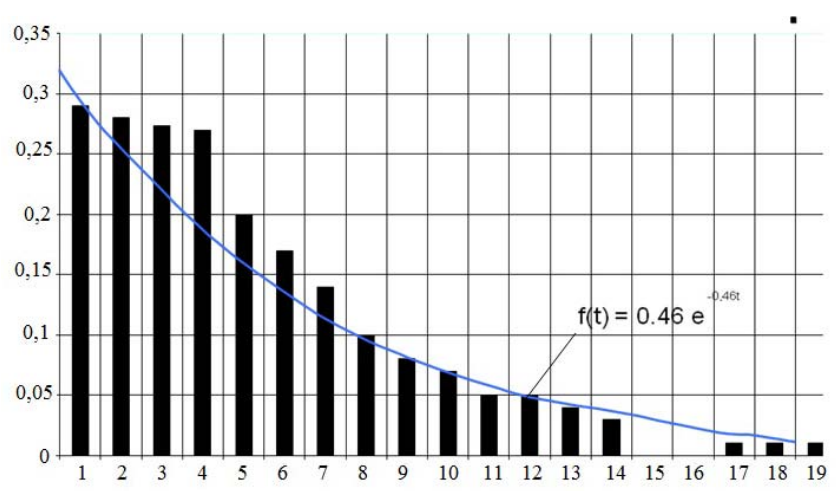

Рис. 3. Гистограмма распределения выходного потока составов со станции за июнь-август 2014

Аналогичные исследования технологических интервалов проведены по основным технологическим линиям приграничной станции, в частности, в парке приема таможенной службой, обработка вагонов на станции; обработка на пункте перегрузки. Результаты исследований показали, что поток обслуживания является простейшим или распределяется по закону Эрланга 2-го порядка. Таким образом, функционирование каждой из подсистем обработки вагонов, документов и информации целесообразно моделировать с использованием хорошо зарекомендовавшего для подобных целей математического аппарата систем массового обслуживания.

Рассмотрим процесс моделирования основных подсистем приграничных станций с изменением ширины колеи.

\section{5. Апробация результатов исследований.} Моделирование подсистемы «приграничная станция - пункт перегрузки вагонов»

Совершенствование технологических процессов работы приграничных передаточных станций не ограничивается только технологией непосредственно приема и обработки поезда с последующей отправкой за границу и наоборот, а также учитывает наличие ширины колеи 1435 мм на железных дорогах других стран.

Технология работы приграничной станции предусматривает наличие входного и выходного потоков поездов, поступающих к обработке на станцию через нерегулярные промежутки времени. Поэтому представим приграничную станцию как систему $S$, которая является однородной марковской цепью с непрерывным временем.

При рассмотрении системы $S$ рассматриваем граф марковской цепи. Вершины и ребра этого графа могут быть оснащены лингвистическими, функциональными или числовыми переменными (быть размеченными). Для приграничной станции для разметки вершин графа ограничимся лингвистической переменной - названием состояния вагона, и численной переменной - вероятностью 
нахождения вагона в этом состоянии в момент времени $t$. Дуги графа оснастим численной переменной - интенсивностью перехода.

Переход из состояния в состояние изображаем в виде графа марковской цепи $S$, который в дальнейшем будем называть графом состояний вагонопотока. Пропуск потока по элементам начинается с блока «приграничная станция за рубежом - главный участок - парк приема». При этом анализируются два элемента: пограничная станция за рубежом (предыдущий элемент) и парк приема (следующий элемент).

Перерабатывающая способность и пункта перегрузки, и пункта смены тележек должна соответствовать входному загруженном вагонопотоку с импортными грузами и не допускать образования очередей таких вагонов в ожидании соответствующих операций в парках прибытия и сортировки.

Технологическое ограничение в системе ранее было вызвано превышением времени обработки информационного потока над продолжительностью обработки вагонопотока. С введением электронного документооборота это ограничение на продолжительность перестает носить существенный характер, и, соответственно, значительно влиять на время нахождения вагонов на станции.

Размеченный граф состояний системы «Приграничная станция за рубежом - главный участок - парк приема» приведен на рис. 4. Грузовой вагон на станции проходит состояния, которые имеют следующие обозначения: С0 - нахождение поезда на приграничной станции за рубежом; С1 получение раскладки поезда по роду подвижного состава, информирование старшего приграничного отряда, инспектора таможни, маневрового диспетчера сортировочного парка, поездного диспетчера о раскладке поезда, котрый будет принят из-за границы; С2 - снятие напряжения и ограждения состава; С3 - проведения погранично-таможенных операций; C4 - наложение закруток и пломбировка вагонов пломбами станции; С5 - отчет оператору при ДСП Е-2 об окончании осмотра; С6 - включения напряжения, опробование автотормозов

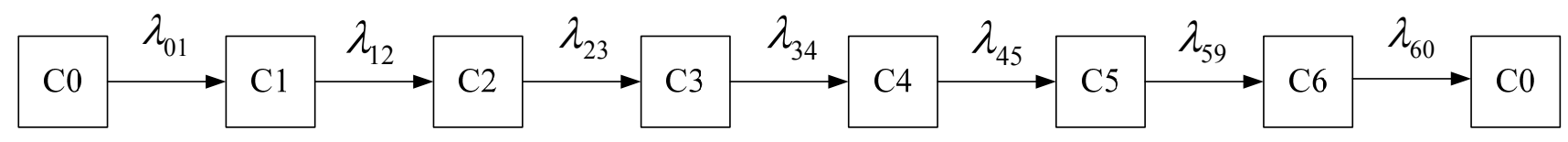

Рис. 4. Граф состояний обращения вагонов на приграничной станции

При этом учтено, что в процессе проведения погранично-таможенных операций вагоны могут быть задержаны по соответствующим причинам, то есть вагоны могут оставаться на путях парка приема.

Размеченный граф состояний системы «Сортировочный парк станции - пункт перегрузки (колея 1435 мм)» приведен на рис. 5. Грузовой вагон в данной системе проходит состояния, которые имеют следующие обозначения: C8 - формирование подач ва- гонов по колее 1435 мм; С9 - подача вагонов на пункт перегрузки; С10 - подготовка подвижного состава под перегрузку; C11 - перегрузка грузов; С12 - составление акта общей формы в случае повреждения иновагона при перегрузке; C13 - технический осмотр выгруженных вагонов; C14 - перестановка пустых вагонов в парк станции; С15 - очистка вагонов колеи 1435 мм после выгрузки

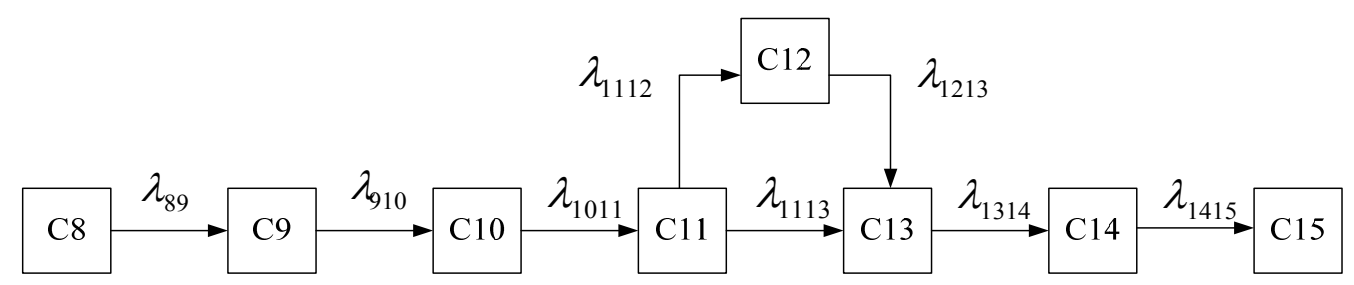

Рис. 5. Граф состояний обращения вагонов по колее 1435 мм в сортировочном парке станции и на пункте перегрузки вагонов

Размеченный граф состояний системы «Сортировочный парк станции - пункт перегрузки (колея 1520 мм)» приведен на рис. 6. Грузовой вагон в данной системе проходит состояния, которые имеют следующие обозначения: C16 - подбор в сортировочном парке вагонов под перегрузку; С17 коммерческий и технический осмотр порожних вагонов; С18 - подача вагонов на пункт перегрузки;
С19 - установление окончательной пригодности порожних вагонов в коммерческом отношении в соответствии с родом импортного груза; С20 перегрузка грузов; С21 - составление акта общей формы в случае повреждения груза при перегрузке; С22 - пломбирования загруженных вагонов; С23 перестановка груженых вагонов в парк станции; С24 - проверка соответствия погрузки и крепления грузов в вагонах 


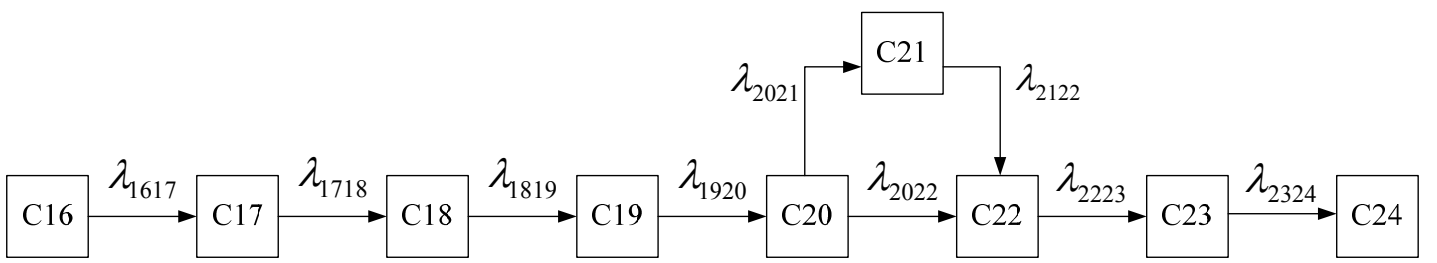

Рис. 6. Граф состояний обращения вагонов по колее 1520 мм в сортировочном парке станции и на пункте перегрузки вагонов

6. Определение параметров подсистемы «Пограничная станция за рубежом - главный участок - парк приема»

В соответствии с технологическим процессом пограничной станции и графом состояний вагонопотока на приграничной станции (рис. 4), рассмотрим следующие условия: в момент времени $t_{0}$ подготовлен для отправки на приграничной станции за рубежом состав из g вагонов, следующих на приграничную станцию украинской железной дороги. При этом предполагаем, что в системе «Приграничная станция за рубежом - главный участок - парк приема» нет других вагонов, следовательно они и не обрабатываются.

Состояние вагонопотока описывается системой дифференциальных уравнений Колмогорова, полученной на основании графа состояний, соответствующим этой цепи, и генератора $\Lambda$ марковской цепи, пример (3) которого приведен ниже.

$$
\Lambda=\left|\begin{array}{ccccccc}
-g & g & 0 & 0 & 0 & 0 & 0 \\
0 & -g & g & 0 & 0 & 0 & 0 \\
0 & 0 & -g & g & 0 & 0 & 0 \\
0 & 0 & 0 & -g & g & 0 & 0 \\
0 & 0 & 0 & 0 & -g & g & 0 \\
g & 0 & 0 & 0 & 0 & -g & g
\end{array}\right| .
$$

7. Определение параметров подсистемы «Сортировочный парк станции - пункт перегрузки (колея 1435 мм)»

Рассмотрим параметры вагонопотока по колее 1435 мм в сортировочном парке приграничной станции и пункта перегрузки согласно графу (рис. 5). Введем следующие условия: в момент времени $t_{0}$ формируется подача из вагонов, следующих на пункт перегрузки. При выполнении перегрузки возможно повреждение вагонов, что по технологии предполагает составление актов общей формы. Параметры вагонопотока в подсистеме «Сортировочный парк станции - пункт перегрузки (колея 1435 мм)» в виде зависимости вероятности времени обслуживания в каждой фазе приведены на рис. 7.

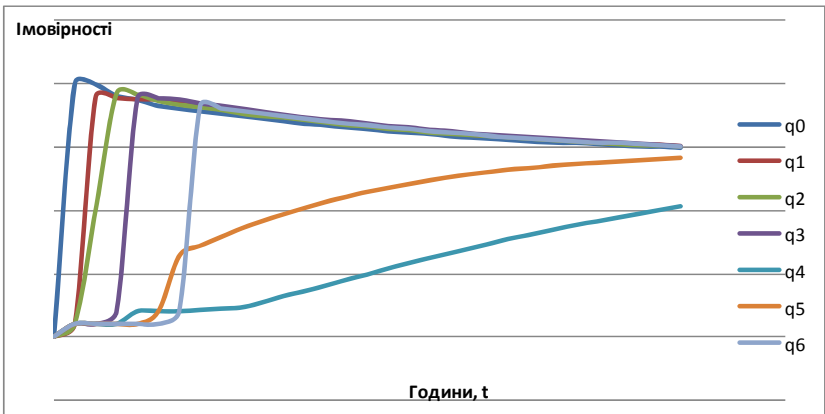

Рис. 7. Вероятность нахождения вагонов в каждой фазе подсистемы «Сортировочный парк станции пункт перегрузки (колея 1435 мм)»

На рис. 7 показаны вероятности нахождения вагонов в каждой фазе подсистемы «Сортировочный парк станции - пункт перегрузки (колея 1435 мм)», которые имеют следующие обозначения: Q0 вероятность нахождения вагонов в состоянии формирования подач по колее 1435 мм; Q1 вероятность нахождения вагонов в состоянии подачи на пункт перегрузки; Q2 - вероятность нахождения вагонов в состоянии подготовки под перегрузку; Q3 вероятность нахождения вагонов в состоянии перегрузки грузов; Q4 - вероятность нахождения вагонов в состоянии составления акта общей формы в случае повреждения иного вагона при перегрузке; Q5 - вероятность нахождения вагонов в состоянии технического осмотра; Q6 - вероятность нахождения вагонов (порожних) в состоянии перестановка в парк станции.

7. Определение параметров подсистемы «Сортировочный парк станции - пункт перегрузки (колея 1520 мм)»

Граф состояний вагонопотока по колее 1520 мм в сортировочном парке пограничной станции и пункта перегрузки (рис. 6), рассмотрим в следующих условиях: в момент времени $t_{0}$ формируется подача из вагонов, следующих на пункт перегрузки. При выполнении перегрузки возможно повреждение груза, что по технологии предполагает составление коммерческого акта. Параметры вагонопотока в подсистеме «Сортировочный парк станции - пункт перегрузки (колея 1520 мм)» в виде зависимости вероятности времени обслуживания в каждой фазе приведены на рис. 8. 


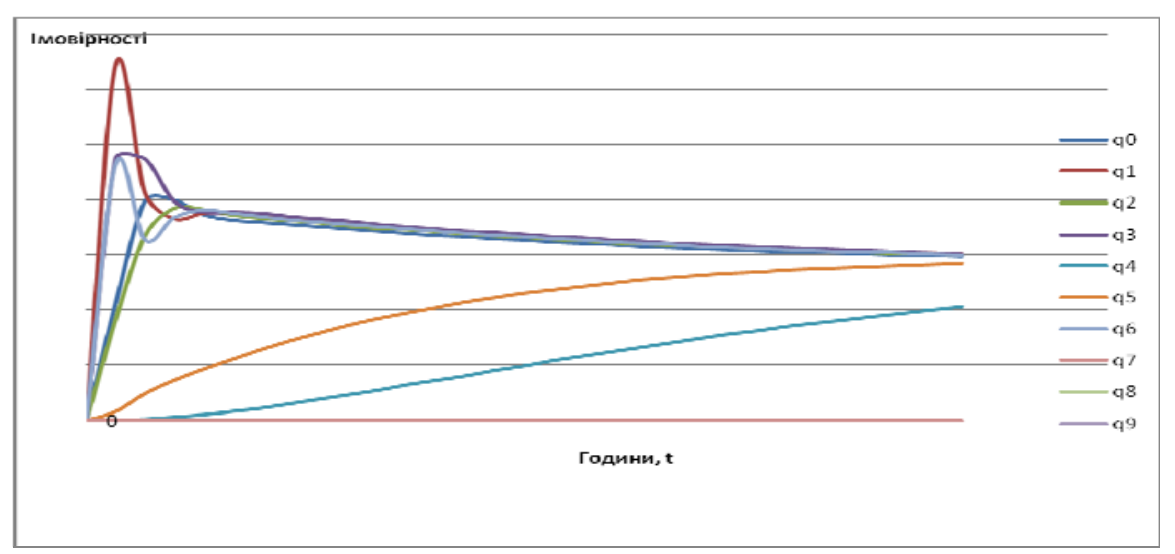

Рис. 8. Вероятность нахождения вагонов в каждой фазе подсистемы «Сортировочный парк станции - пункт перегрузки (колея 1520 мм)»

На рис. 8 показаны вероятности нахождения вагонов в каждой фазе подсистемы «Сортировочный парк станции - пункт перегрузки (колея 1520 мм)», которые имеют следующие обозначения: Q0 вероятность нахождения в состоянии подбор в сортировочном парке вагонов под перегрузку; Q1 вероятность нахождения вагонов (порожних) в состоянии коммерческого и технического осмотров; Q2 - вероятность нахождения вагонов в состоянии подачи на пункт перегрузки; Q3 - вероятность нахождения вагонов в состоянии установления окончательной пригодности в коммерческом отношении в соответствии с родом импортного груза; Q4 - вероятность нахождения вагонов в состоянии перегрузки грузов; Q5 - вероятность нахождения вагонов в состоянии составления акта общей формы в случае повреждения груза при перегрузке; Q6 - вероятность нахождения вагонов (загруженных) в состоянии пломбирования; Q7 вероятность нахождения вагонов в состоянии перестановки в парк станции; Q8 - вероятность нахождения вагонов в состоянии проверки соответствия погрузки и крепления грузов.

C помощью полученных зависимостей возможно исследовать переходные режимы в системах «Приграничная станция за рубежом главный участок - парк приема» и «Сортировочный парк станции - пункт перегрузки», а также определять среднюю численность вагонов в каждом состоянии, время ликвидации очередей и выхода системы в стационарный режим работы при заданном техническом оснащении и объеме вагонопотоков.

Предложенные научные подходы позволяют оценить характеристики вагонопотока на приграничной станции:

- среднее число заявок (вагонов) в очереди в каждой фазе и системе;

- среднее число заявок (вагонов) в очереди и на обслуживании в каждой фазе и системе;

- среднее время ожидания для заявки (вагона) в очереди на обслуживание;

- среднее время пребывания заявки (вагона) в системе (в очереди и под обслуживанием), а также другие характеристики, без построения графической модели.
Использование разработанных моделей и результатов моделирования в составе автоматизированных рабочих мест и систем поддержки принятия решений персонала приграничных станций позволит повысить эффективность работы и улучшить показатели использования вагонов.

\section{8. Выводы}

В процессе моделирования установлено, что технология работы таких подразделений на станции, как таможенная служба, служба санитарного контроля, пограничная товарно-экспедиторская контора, контора передач, которые связанны с обработкой документов и вагонов, часто является ограничивающей продолжительность нахождения вагонов в системе, поскольку требует значительной продолжительности времени обработки документов на вагоны. Кроме того выявлено, что технология работы станции не в полной мере обеспечивает параллельность выполнения операций по обработке документов на каждый поезд, наблюдаются дублирующие друг друга операции (например, проверка всего комплекта документов сотрудниками таможни и таможенными брокерами).

Согласно полученным оценкам по эмпирическим данным, средний простой вагона с импортным грузом на приграничной станции при перегрузке вагонов 1435/1520 мм составляет 16,4 ч. Внедрение предложенного научного подхода на базе существующих АРМ позволит сократить простой вагонов под ожидания до начала операций на 0,25 ч.

\section{Литература}

1. Венцель, Е. С., Исследование операций [Текст] / Е. С. Венцель. - Москва : Транспорт, 1988. - 116 с.

2. Kantor, M. Electronic Data Interchange (EDI) [Text] / M. Kantor, J. H. Burrows // National Institute of Standards and Technology. - 2008. - Vol. 8. - P. 32-38.

3. Ломотько, Д. В. Удосконалення технології роботи прикордонних станцій в умовах єдиного інформаційного простору [Текст] / Д. В. Ломотько, А. Л. Обухова, О. В. Ковальова // Зб. наук. праць УкрДАЗТ. - 2011. - Вип. 127. C. 5-10.

4. Калтахчан, А. Т. Математическая постановка задачи выбора оптимальних параметров проектирования и эксплуатации грузовых объектов [Текст] / А. Т. Калтахчан // Труды МИИТа. - 1978. - Вып. 1. - С. 16-20. 
5. Коваленко, И. Г. Методы расчета высоконадежных систем [Текст] / И. Г. Коваленко, Н. Ю. Кузнецов. - М. : Радио и связь, 1988. -176 с.

6. Котенко, А. Н. Математические модели массового обслуживания вагонов на грузовых [Текст] / А. Н. Котенко // Концепція підвищення ефективності вантажних перевезень на залізничному транспорті. Міжвуз. зб. наук. праць. - 1998. - № 33. - С. 33-35.

\section{References}

1. Ventsel, E. (1988). Operations research. Moscow, USSR: Transport, 116.

2. Kantor, M., Burrows J. (2008). Electronic Data Interchange (EDI). National Institute of Standards and Technology, 8, 32-38.
3. Lomotko, D., Obukhova, A., Kovalova, O. (2011). Improving the technology of border stations in terms of a common information space, Collection of scientific works UkrDAZT, 127, 5-10.

4. Kaltahchan, A. (1978). The mathematical formulation of the problem of choosing the optimal parameters of the design and operation of cargo facilities. Proceedings MIIT, 1, 16-20.

5. Kovalenko, I., Kuznecov, N. (1988). Methods of calculation of highly reliable systems. Moscow, USSR: Radio and Communications, 176.

6. Kotenko, A. (1998). Mathematical models of queuing cars on freight. Collection of scientific papers between universities, 33, 33-35.

Дата надходження рукопису 20.11.2014

\begin{abstract}
Ломотько Денис Викторович, доктор технических наук, профессор, кафедра транспортные системы и логистика, Украинская государственная академия железнодорожного транспорта, пл. Феербаха, 7, г. Харьков, Украина, 61050

E-mail: den@kart.edu.ua

Обухова Анна Леонидовна, кандидат технических наук, доцент, кафедра управления грузовой и коммерческой работой, Украинская государственная академия железнодорожного транспорта, пл. Фейербаха, 7, г. Харьков, 61050

E-mail: anya.obukhova@gmail.com

УДК 502.5+614.7:049.3

DOI: 10.15587/2313-8416.2014.32102

\section{КОМПЛЕКСНА ОЦНКА ЕКОЛОГІЧНОЇ НЕБЕЗПЕКИ ПРОМИСЛОВОГО ПІДПРИЄМСТВА НА ПРИКЛАДІ ЗМЇ̈ВСЬКОЇ ТЕС}

\author{
(C) О. В. Рибалова, С. В. Бслан
}

В статті представлено новий підхід до комплексної оцінки ризику для здоров'я населення. За представленою методикою вперше дана комплексна оцінка впливу Зміївської ТЕС на стан довкілля. Визначено ймовірність збільшення захворюваності населення від впливу теплової електростаниії на навколишнє природне середовище

Ключові слова: комплексна оцінка; атмосферне повітря; поверхневі води; грунт; ризик; здоров'я населення

A new approach to integrated risk assessment for public health is presented in the article. According to the presented method for the first time in the article was assessed the impact of Zmiivska TPP on the environment. It is determined the probability of population morbidity increasing from the influence of thermal power plant on the environment

Keywords: comprehensive assessment; air; surface water; soil; risk; public health

\section{1. Вступ}

Відповідно до Конституції України, закону України "Про охорону навколишнього природного середовища" та Кодексу цивільного захисту України основними пріоритетами державної політики $є$ забезпечення техногенної та природної безпеки, комфортних i безпечних умов життєдіяльності населення, збереження природного середовища. Але останніми роками спостерігається значне погіршення стану навколишнього природного середовища, особливо в промислових регіонах країни. Основними причинами погіршення екологічного стану багатьох регіонів $є$ зношеність і застарілість технологічного обладнання промислових підприємств, житлово комунального і сільського господарств, неефектив- ність використання природних ресурсів, накопичення відходів, що зумовлює збільшення захворюваності населення.

За результатами аналізу стану здоров'я населення України фахівці відмічають сталу негативну тенденцію зростання захворюваності та поширеності хвороб, зменшення абсолютної кількості населення за рахунок збільшення смертності, прогнозується подальше зростання негативних змін цих показників, що стає загрозливим для національної безпеки [1].

Таким чином, визначення рівня екологічної небезпеки промислових підприємств на основі комплексної оцінки ризику для здоров'я населення є дуже актуальною задачею при вирішенні проблеми 